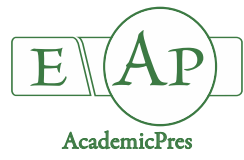

Available online: www.notulaebotanicae.ro

\title{
Cytological Investigation in Two Mutants of the Hybrid Grapevine 'Niagara'
}

\author{
Neiva Izabel PIEROZZI ${ }^{1 *}$, Mara Fernandes MOURA ${ }^{2}$ \\ ${ }^{1}$ Instituto Agronômico de Campinas (IAC), Centro de Recursos Genéticos Vegetais, 1481 Barão de Itapura Av., \\ Campinas, CEP:13020-902, Brazil; pierozzi@iac.sp.gov.br (*corresponding author) \\ ${ }^{2}$ Instituto Agronômico de Campinas (IAC), Centro Avançado de Pesquisa de Frutas, 1500 Luiz Pereira dos Santos Av., \\ Jundiai, CEP:13214-820,Brazil;mouram@iac.sp.gov.br
}

\begin{abstract}
'Niagara' is a hybrid table grape $(V$. vinifera $\times V$. labrusca). Several spontaneous somatic mutants from this grapevine have already been described. However, cytological information about these mutants is scarce. Therefore, studies in the microsporogenesis have been carried out in two of these mutants, a seedless and a large berry mutant (giant mutant). A low percentage of abnormalities such as precocious chromosome segregation, bivalent not aligned, laggard and stickiness chromosomes were seen in both mutants. A merging process of microspores was observed in several tetrads in the seedless mutant: the microspore came together by large cytoplasmic bridges giving rise to a large and amorphous single-celled tetrad, which eventually collapsed. The giant mutant showed $10.29 \%$ of tetrads with microcytes. However, these tetrad abnormalities did not hinder pollen viability. Significant differences were seen concerning stomata and pollen grain sizes, stomata frequency and anther number per flower between the mutants. The chromosome count at diakinesis $(n=19)$ and in diploid tapetal cells $(2 n=38)$ clarified the fact that the seedless somatic mutation was not associated with any ploidy event. Conversely, the giant mutant showed $n=38$ at diakinesis and $2 n=76$ in diploid tapetal cells, pointing to a case of spontaneous chromosome duplication. Since these abnormalities did not disturb the percentage of pollen viability very much, in both mutants (higher than $86 \%$ ), the seedless one may be used as a male parent in crossing, regarding the desirable seedlessness character, while the mutant giant may be employed as female parent for the obtainment of seedless triploid plants.
\end{abstract}

Keywords: meiotic abnormalities; microsporogenesis; pollen fertility; seedlessness; spontaneous autotetraploid; Vitis

\section{Introduction}

The cultivation of vines has been a significant economic activity around the world. Thousands of well-succeeded spontaneous or artificial hybrid varieties and cultivars have arisen, have been adapted to the environment and have been cultivated for different purposes. The clonal propagation of these varieties through hard cuttings is a strategic tool often used in viticulture to ensure the maintenance of the same genotype. However, a somatic mutation may sometimes occur in grapevines, which has been accountable for the onset of new promising varieties (Collet et al., 2005). A spontaneous somatic mutation is very often noticed in young shoots displaying morphological differences. Depending on the desirable features, the clonal variants of the grapevine display can be selected and further employed for different purposes, such as rootstock, table grapes for consumption or for jam, juice and wine production (Boss and Thomas 2002; Collet et al., 2005; This et al., 2006). Among the most common noticeable mutations that might appear in the grapevine, are those related to berry color and size, amount of leaf trichomes, tendril numbers, inflorescence morphology and size, flower number and morphology, bunch size and plant dwarfism, for instance (Boss and Thomas, 2002; Vezzulli et al., 2012). Other mutations result in seedless berries as well as in larger sized berries.

The seedlessness or apireny is a desirable character for table grapes and raisins. Seedlessness in Vitis can be induced in two ways, via stenospermocarpy (abortion of embryo) or parthenocarpy (fruit development in the absence of pollination). Seedlessness in interspecific hybrids of grapevines can also appear as a spontaneous somatic mutation as in 'Concord' or in 'Venus' ( $V$. vinifera $\times V$. labrusca) (Ramming, 2008). Another type of mutation, though not so frequent, called autotetraploidy (somatic chromosome doubling) can arise in a branch of a diploid grapevine cultivar. This spontaneous somatic mutation can initially be detected by the enlarged leaves and berries, and further by chromosome counts as well as by stomata and pollen grain size measures (Reisch and Pratt, 1996). 
914

'Niagara' grapevine is an interspecific hybrid of $V$. vinifera and $V$. labrusca obtained through artificial crossing. Very much appreciated in Brazil as a table grape as well as juice, 'Niagara' has enhanced profitability for growers. So far eight spontaneous somatic mutants of 'Niagara' have already been described and considered as new cultivars. They differ mainly in regards to the berry number per bunch, color, shape and size (Sousa, 1959; Maia, 2012). The mutant 'Niagara Rosada Gigante' ('Giant Rosy Niagara') was described and named by Sousa (1959). Due to the large size of its berries, it was assumed as being a case of spontaneous chromosome duplication (Maia, 2012). A seedless mutant with small berries and very small seeds was later observed and described by Pires et al. (1988) and named 'Seedless Niagara'. As a result, it was concluded to be a case of stenospermocarpy. However, despite the outstanding characteristics of these two somatic mutants, there are no studies on chromosome behavior during the microsporogenesis or attempts, for the least, to ascertain the degree of pollen fertility in these mutants. In fact, information is limited in literature concerning male meiosis behavior of grapevine cultivars, hybrids or wild species.

Analyses regarding chromosomal behavior during meiosis and the evaluation of pollen fertility are conventional basic studies belonging to the pre-breeding steps, recommended for a better characterization and discrimination of new mutants, clones, bud sports and other types of propagating material. Moreover, these basic studies have also been essential in the maintenance of reliable germplasm banks. As part of the grapevine improvement, cytological researches were developed to ascertain the normality of the microsporogenesis of two outstanding mutants, a seedless and a large berry (giant). Some other traits of these mutants were also checked, concerning chromosome number in somatic cells, pollen grain fertility and size, stomatal size and frequency, which could be related to these somatic mutants.

\section{Materials and Methods}

\section{Plant materials}

The seedless mutant 'Seedless Niagara' and the large berry mutant 'Niagara Rosada Gigante' (giant mutant) arose spontaneously in the 'Niagara Rosada' grapevine. These were selected and propagated by hardwood cuttings. They are also considered as cultivar belonging to the Vitis germplasm of IAC growing at Fruit Center (IAC) in Jundiaí municipality, São Paulo state. Plants of each mutant were employed for the studies. Young inflorescences with flower buds at different stages of development were collected over three consecutive years, 2014 to 2016. The flower buds were fixed in Carnoy fluid (ethanol 99\% and acetic acid $3: 1 \mathrm{v} / \mathrm{v}$, respectively) and stored under $-20{ }^{\circ} \mathrm{C}$ until cytological preparations.

\section{Cytological preparations for analyses}

Anthers of some fixed young buds were removed and squashed in $1.2 \%$ acetic carmine solution for cytological analyses which were carried out during the distinct meiotic phases from pachytene to pollen grains and the percentage of chromosome abnormalities was scored. More than 700 pollen mother cells (PMCs) were evaluated for each meiotic phase in each mutant. Chiasma average number per cell and per chromosome with the standard deviation was calculated using 100 cells at metaphase I in each mutant. Meiotic Index (MI = the percentage of normal tetrads) was also obtained. Silver impregnation (Howell and Black, 1980) was applied for a better visualization of the bivalent attached to the nucleolus at pachytene and diakinesis phases and 2,000 cells per mutant were scored at pachytene phase.

Pollen grain fertility was estimated by cytoplasmic stainability with Alexander A4 dye (Alexander, 1980). Four thousand pollen grains were scored per cultivar. In addition, the percentage of pollen germination was also obtained. Pollen samples were collected from newly opened flowers and cultured on a medium prepared according to Park et al. (2002). The medium was poured on a slide and after two minutes the pollen grains were shed over the slide and kept for 24 hours at $26^{\circ} \mathrm{C}$. Five slides per cultivar were prepared and 500 pollen grains were scored per cultivar.

The size (area $\mu \mathrm{m}-2)$ of the fertile pollen grains was also calculated, considering its ellipsoidal shape and 120 pollen grains of each plant were measured.

The cellulose acetate technique was applied for the obtainment of the stomatal size and the stomatal frequency. Five expanded leaves from the intermediate region of each grapevine and of each cultivar were collected in the morning and 125 stomata of each plant were measured and scored per leaf area $(\mathrm{mm}-2)$.

In addition, two hundred buds of each cultivar were chosen at random, opened and anther number scored. F-test was applied to compare the values obtained. Apart from chromosome counts in meiosis, the chromosomes of some diploid tapetal cells were counted. Photomicrographs were taken under an 'Olympus Vanox' optical photomicroscope using a black and white ILFORD film ASA 125. F-test (Pimentel-Gomes and Garcia, 2002) was applied to compare the mean values obtained to chiasma frequency, meiotic index, pollen stainability, germination and size (area), stomatal size and frequency, stamen number in floral buds, stomata size and frequency.

\section{Results}

Irregularities at low percentages were observed during the microsporogenesis in both mutants (Table 1, Figs. 1 and 2). No chromosome configuration of chain, ring or bridge were observed neither at diakinesis nor at metaphase I, which could point to chromosome translocation or inversion and that may have gone unnoticed or may have not been detected at pachytene phase. One bivalent attached to the nucleolus at pachytene prevailed in the seedless mutant (92.79\%) while two bivalents prevailed in the giant mutant $(91.78 \%)$ at the same phase. Nineteen bivalents were observed at diakinesis in the seedless mutant and 38 bivalents in the giant mutant pointing to a case of autotetraploidy (Fig. 2 A, B).

Despite the autotetraploid condition, no multivalent or monovalent chromosomes were recorded at diakinesis or metaphase I in the giant mutant.

The most common abnormalities scored were chromosome stickiness, bivalents not aligned, precocious 
Table 1. Percentage (\%) of some meiotic abnormalities in pollen mother cells (PMCs) of 'Seedless Niagara' (Sedless) and 'Niagara Gigante' (Giant). Chrom $=$ chromosome

\begin{tabular}{|c|c|c|c|c|c|}
\hline \multicolumn{2}{|c|}{$\mathrm{N}^{\circ}$ Cells score: } & \multirow{2}{*}{ Phase } & \multirow{2}{*}{ Observations } & \multicolumn{2}{|c|}{ \% abnorm., in PMCs } \\
\hline Sedless & Giant & & & Sedless & Giant \\
\hline \multirow[t]{2}{*}{712} & 722 & Dia: & Chromosome stickiness & & \\
\hline & & & Two nucleoli & 0.00 & 0.55 \\
\hline \multirow[t]{2}{*}{836} & 761 & Met I: & Precocious chrom. segregation & 1.08 & 1.97 \\
\hline & & & Non oriented bivalent & 0.60 & 2.10 \\
\hline \multirow[t]{3}{*}{712} & 775 & Ana I: & Chromosome stickiness & 0.42 & 1.42 \\
\hline & & & Laggard chromosomes & 0.42 & 2.84 \\
\hline & & & Three sets of chromosomes & 0.00 & 0.13 \\
\hline \multirow[t]{2}{*}{740} & 721 & Met II: & Precocious chrom segregation & 0.54 & 0.55 \\
\hline & & & Three sets of chromosomes & 0.27 & 0.42 \\
\hline \multirow[t]{3}{*}{719} & 740 & Ana II: & Chromosome stickiness & 0.83 & 1.22 \\
\hline & & & Laggard chromosomes & 0.00 & 0.54 \\
\hline & & & Five sets of chromosomes & 0.00 & 3.11 \\
\hline \multirow[t]{2}{*}{714} & 745 & Telo II: & Five or six sets of chromosomes & 0.00 & 0.67 \\
\hline & & & Total abnormalities (\%) & 4.58 & 16.49 \\
\hline
\end{tabular}
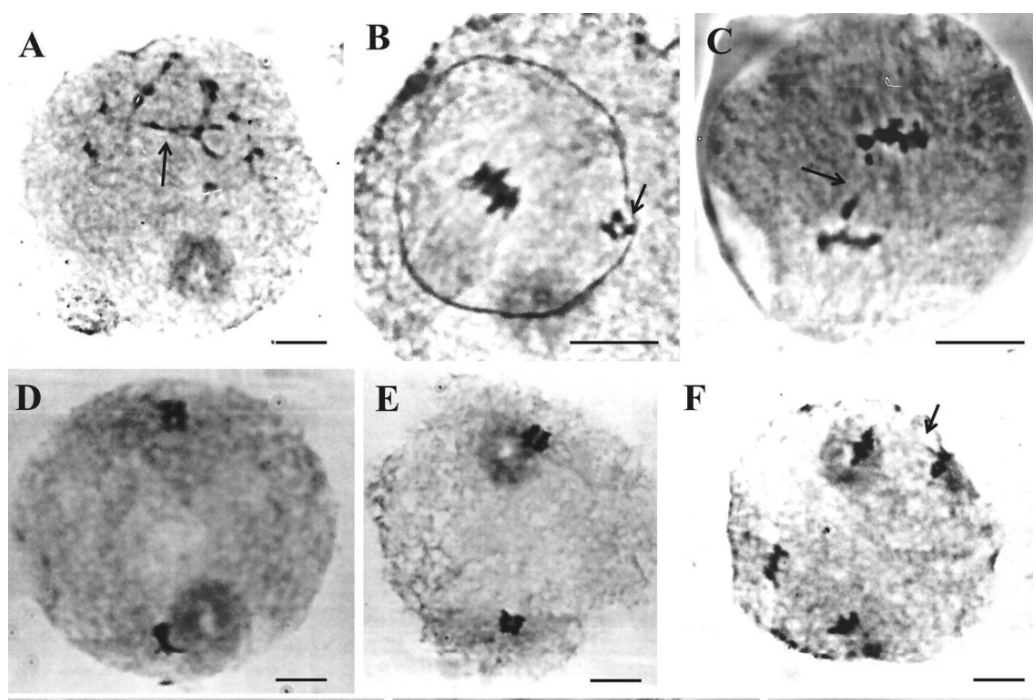

\section{$\mathbf{F}$}
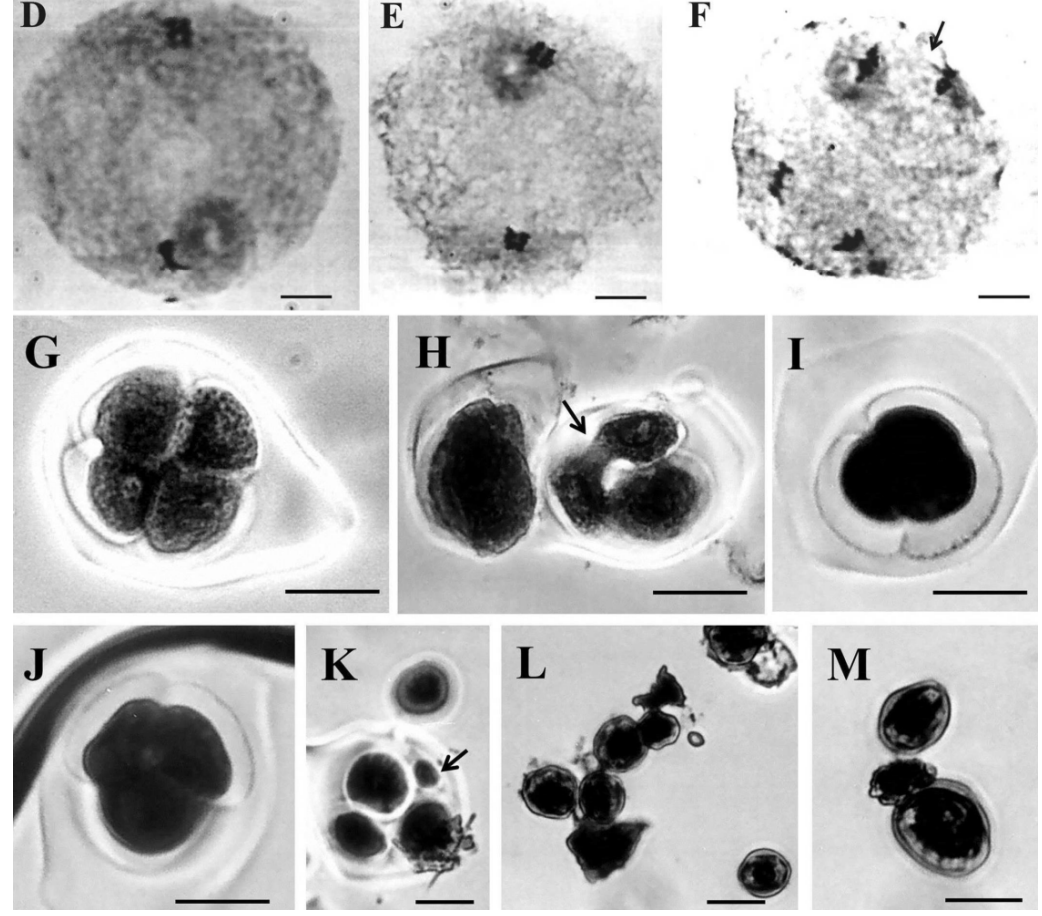

$\mathbf{M}$

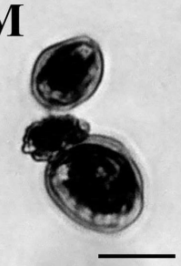

Fig. 1. Some meiotic phases of the seedless mutant 'Seedless Niagara'. (A) chromosome stickiness at diakinesis, metaphase I with: (B) non-oriented chromosomes; (C) laggard chromosome; (D)metaphase II; (E) early anaphase II; (F) chromosome stickiness at anaphase II; $(\mathrm{G})$ beginning of microspore fusion at tetrad stage; $(\mathrm{H})$ tetrad with fusion and degeneration of microspores; (I) and (J) early process of microspore fusion; $(\mathrm{K})$ tetrad with one microcyte; (L) fertile pollen grains; (M) pollen grains with different sizes. $\mathrm{Bar}=10 \mu \mathrm{m}(\mathrm{A}$ to $\mathrm{F})$ and $20 \mu \mathrm{m}(\mathrm{G}$ to $\mathrm{M})$ 
916

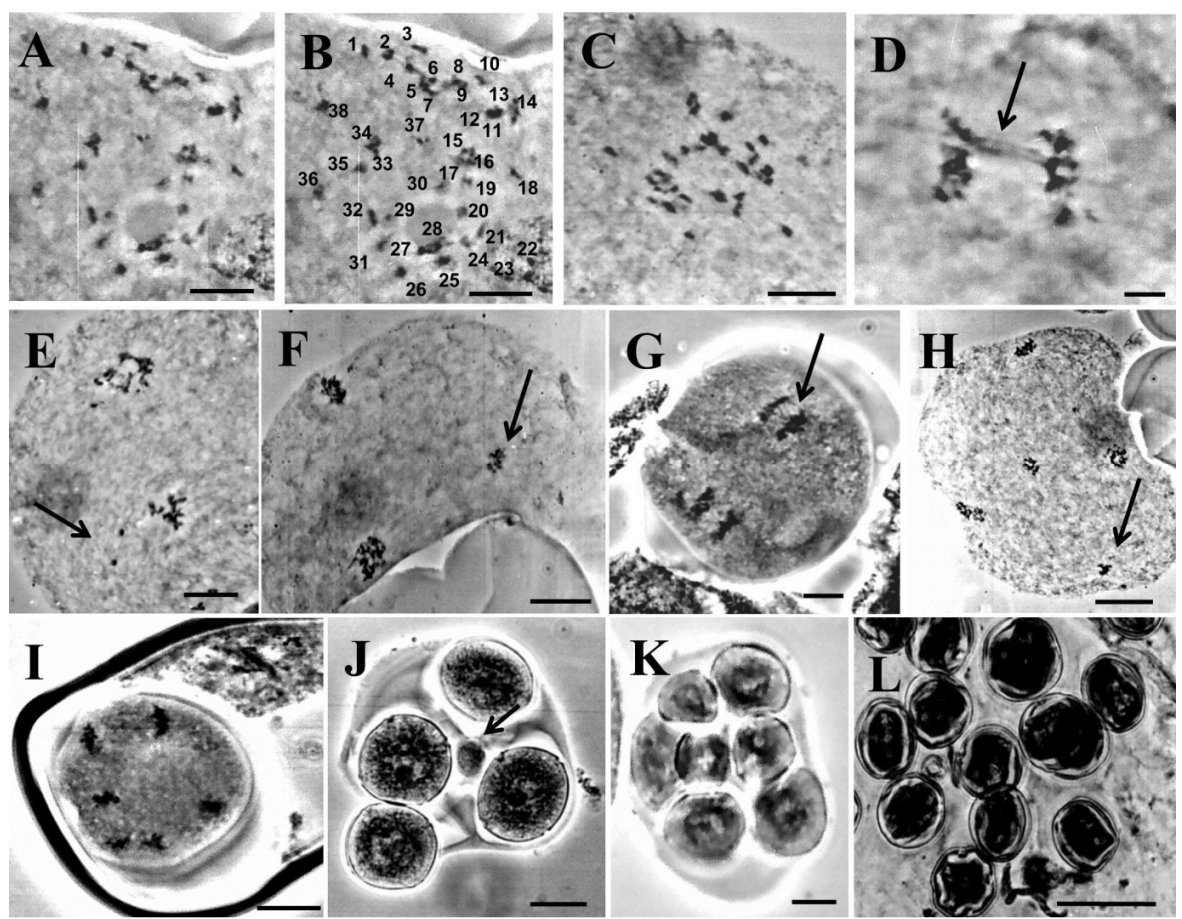

Fig. 2. Meiotic phases of the giant mutant 'Niagara Rosada Gigante'. (A) diakinesis with chromosome stickiness and (B) chromosome count; (C) metaphase I; (D) chromosome stickiness at anaphase I; (E) metaphase II with precocious chromosome segregation; (F) three sets of chromosomes at metaphase II; (G) anaphase II with chromosome stickiness; (H) telophase II with 5 sets of chromosomes and (I) with 6 sets of chromosomes; (J) tetrad with one microcyte; $(\mathrm{K})$ polyad with 7 microspore; (L) different sizes of pollen grains. Bar $=10 \mu \mathrm{m}($ A to $\mathrm{K})$ and $20 \mu \mathrm{m}(\mathrm{L})$

chromosome segregation, laggard chromosomes, two and three spindles, five sets of chromosomes (Table 1). Both mutants displayed a low percentage of (a) chromosome stickiness at diakinesis, anaphase I and II; (b) precocious chromosome segregation at metaphase I and II; (c) nonoriented bivalent at metaphase I; (d) laggard chromosomes at anaphase I and (e) three sets of chromosomes at metaphase II (Table 1, Figs. 1A to C and F; Fig. 2A, D to $\mathrm{G})$. The total percentage of abnormalities was higher in the giant mutant (16.49\%) than in the seedless one (4.58\%).

A high percentage of normal tetrads prevailed in both mutants which meant a high Meiotic Index (MI) but tetrads with one (Fig. 1K, Fig. 2J) or two microcytes also occurred (Table 2).

Table 2. Mean values for number of chiasma per cell and chromosome, percentage of normal (Meiotic index $=\mathrm{MI}$ ) and abnormal tetrads, pollen grain fertility, germination and grain size $\left(\mu \mathrm{m}^{2}\right)$ for both mutants, seedless and giant. Mean values followed by different letters $=$ significant at $5 \%$ after $\mathrm{F}$ test; IV = tetrad

\begin{tabular}{|c|c|c|}
\hline $\mathrm{N}^{\circ}$ chiasma per: & Seedless & Giant \\
\hline Cell & $37.55 \pm 0.59^{\mathrm{a}}$ & $75.16 \pm 0.59^{b}$ \\
\hline Chromosome & $1.98 \pm 0.03^{\mathrm{a}}$ & $1.97 \pm 0.03^{\mathrm{a}}$ \\
\hline \multicolumn{3}{|l|}{ Tetrads \%: } \\
\hline Normal: (MI) & $94.98 \pm 1.57^{\mathrm{a}}$ & $89.09 \pm 3.79^{b}$ \\
\hline \multicolumn{3}{|l|}{ Abnormals: } \\
\hline Dyads & 0.00 & 0.05 \\
\hline Triads & 0.00 & 0.00 \\
\hline IV + 1 microcyte & 0.62 & 10.29 \\
\hline IV +2 microcytes & 0.18 & 0.57 \\
\hline Polyad & 0.00 & 0.16 \\
\hline Wrinkled cytoplasm & 0.00 & 0.90 \\
\hline Merged microspores & 4.22 & 0.00 \\
\hline Pollen stainability & $93.79 \pm 2.65^{\mathrm{a}}$ & $86.65 \pm 2.26^{b}$ \\
\hline Pollen germination & $38.74 \pm 3.29^{\mathrm{a}}$ & $42.48 \pm 6.86^{a}$ \\
\hline Pollen grain size (area) & $427.56 \mu \mathrm{m}^{2} \pm 78.84^{\mathrm{a}}$ & $698.71 \mu \mathrm{m}^{2} \pm 106.93^{\mathrm{b}}$ \\
\hline
\end{tabular}


The giant mutant displayed a higher percentage of tetrads with one microcyte (10.29\%) and a lower mean value for the MI when compared to the seedless mutant. The occurrence of polyads was at low percentage (Table 2, Fig. $2 \mathrm{~K}$ ). Nearly $4.2 \%$ of tetrads of the seedless mutant showed a degenerative process. The microspores came closer and merged giving rise to monads with different degrees of wrinkling (Figs. $1 \mathrm{G}$ to J). Despite these abnormalities pollen viability was higher, $93.79 \% \pm 2.65$ in seedless (Figs. 1L and $\mathrm{M})$ and $86.65 \% \pm 2.26$ in giant mutant (Fig. $2 \mathrm{~L}$ ) and the differences were significant by F-test. The higher mean value for pollen grain size was observed in the giant mutant (Table 2). Both mutants however did not differ concerning the percentage mean value of pollen grain germination, which was lower than the percentage of pollen viability estimated by the cytoplasm stainability (Table 2).

Mutants differed in regards to the mean value of the number of chiasma per cell as expected, due to a different chromosome number, however not considering chiasma number per chromosome $(1.98 \pm 0.03$ for the seedless and $1.97 \pm 0.03$ for the giant mutant) (Table 2).

Chromosome counts in diploid tapetal cells confirmed the observation at diakinesis that the seedless mutant 'Niagara Rosinha' is a diploid $(n=19 ; 2 n=38)$ and the giant mutant 'Niagara Rosada Gigante' is a tetraploid $(n=38$; $2 n=76$ ) (Fig. 3).

The seedless 'Seedless Niagara' and the giant 'Niagara Rosada Gigante' differed in relation to the stamen number per flower bud, which varied from four to seven (Table 3). A prevalence of five stamens per floral buds $(52.59 \%)$ was observed in the seedless and six stamens $(58.07 \%)$ in the giant mutant, which also displayed a few buds with four stamens.

They also differed considering the length and width of the stomata as well as the frequency of the stomata (Table 3). The seedless mutant showed a lower mean value for the size of the stomata but a higher frequency of stomata when compared to the giant mutant.

Table 3. Mean values for the percentage of stamen numbers in floral buds, stomata size and frequency in 'Seedless Niagara' (Seedless) and 'Niagara Gigante' (Giant). Mean values followed by different letters = significant at $5 \%$ after F-test

\begin{tabular}{ccc}
\hline Stamen number: & Seedless & Giant \\
\hline $\mathbf{4}$ & $0.00 \% \pm 0.00^{\mathrm{a}}$ & $32 \% \pm 0.73^{\mathrm{b}}$ \\
$\mathbf{5}$ & $52.59 \% \pm 2.22^{\mathrm{a}}$ & $58.71 \% \pm 3.06^{\mathrm{b}}$ \\
$\mathbf{6}$ & $45.90 \% \pm 1.56^{\mathrm{a}}$ & $6.70 \% \pm 0.61^{\mathrm{b}}$ \\
7 & $1.51 \% \pm 0.66^{\mathrm{a}}$ & $31.35 \mu \mathrm{m} \pm 0.75^{\mathrm{bb}}$ \\
Stomata size: & & $15.07 \mu \mathrm{m} \pm 2.72^{\mathrm{ba}}$ \\
Length & $25.06 \mu \mathrm{m} \pm 1.09^{\mathrm{aa}}$ & $116.46 \pm 4.72^{\mathrm{b}}$ \\
Width & $13.95 \mu \mathrm{m} \pm 0.70^{\mathrm{aa}}$ & $173.83 \pm 3.16^{\mathrm{a}}$ \\
\hline
\end{tabular}
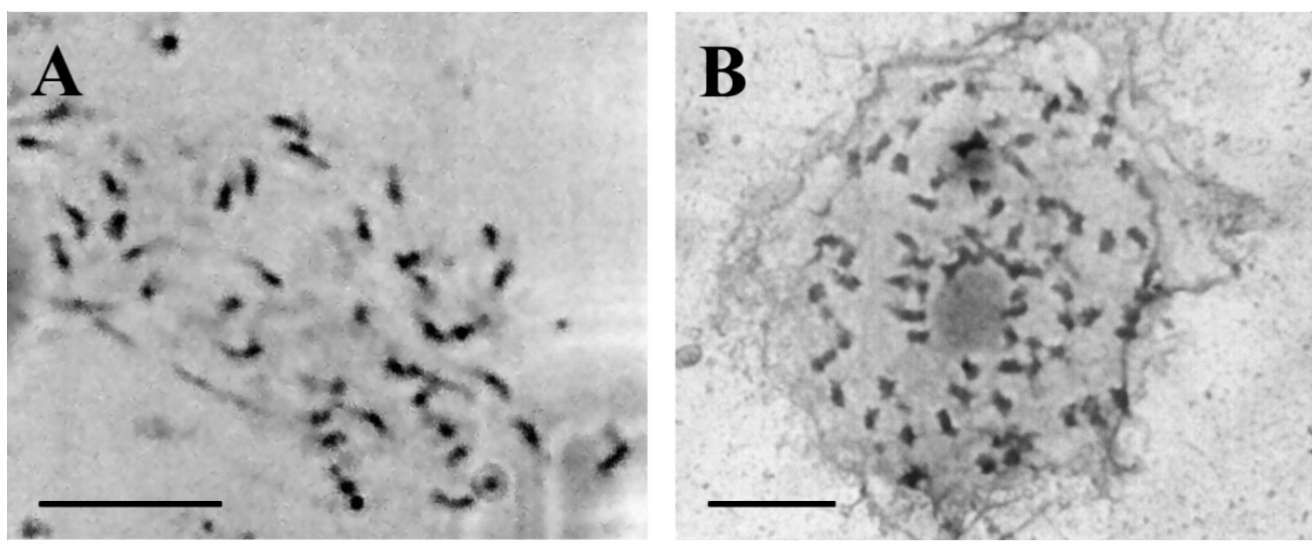

Fig. 3. Mitotic chromosome of tapetal cell of (A) seedless mutant 'Seedless Niagara' $(2 n=38)$ and (B) giant mutant 'Niagara Rosada Gigante' $(2 n=76)$. Bar $=10 \mu \mathrm{m}$

\section{Discussion}

The cytological analyses done in the microsporogenesis of spontaneous autotetraploids as Psidium guava (Srivastava, 1977), Chrysanthemum segetun, C. morifolium and C. leucanthemum cytotypes (Gupta et al., 2013), and in $V$. vinifera 'Riesling' (Staudt and Kassrawi, 1972a) have

shown different degrees of abnormalities reflecting in pollen sterility. In the same way, colchicine-induced autotetraploids of grapevines 'Barbera' (Me et al., 1984), 'Red Pearl', 'Yufu' and 'Cannon Hall Muscat' (Park et al., 2002), for instance, also exhibited a disturbed meiosis with 
918

multivalent associations, non-oriented bivalents, chromosome laggards and stickiness. Meiosis with univalent chromosomes and tetravalent associations was also reported in the artificial autotetraploid 'Concord' ( $V$. labrusca $\times V$. vinifera) (Olmo, 1952). However, despite the spontaneous chromosome duplication occurred in 'Niagara Rosada Gigante' mutant $(V$. labrusca $\times V$. vinifera $)$ it was only observed bivalent chromosomes instead of multivalents and/or monovalents, pointing to a cytological diploidization. This regular meiotic behavior may be due to (a) parental genomic affinities giving rise to a stable meiosis; or on the contrary: (b) a subtle divergence between parental genomes favoring a betterment chromosome pairing; and/or: (c) the small size of all chromosomes which favored only bivalent formation. Kumar et al. (2015) also observed low percentage of abnormalities in the colchiploid Brassica fruticulosa $(4 x=32)$. The authors attributed this to a certain heterozygosity of the parental genotypes which may explain the reduction of quadrivalent frequency to considerable extent in the tetraploid state. The less similar the parental genomes due to hybridization or to small cryptic changes, for instance, the fewer the number of quadrivalents at metaphase I due to the tendency to a preferential pairing between identical homologous partners or homologous of the same genome (Benavente and Orellana, 1991; Le Comber et al., 2010). It has not been ignored that few and small expected differences between the parental genomes might have contributed to chromosome pairing fidelity in the autotetraploid giant mutant, possibly favoring a trend to disomic inheritance. Nevertheless, it is impossible, to infer with certainty whether this is true at genic level, i.e., if the giant mutant has been behaved as a diploid or if it has a tetrassomic inheritance. Consistent studies in the segregation of some expressive morphological characters ought to be carried out geared towards conclusions that are more reliable.

Regular chromosome pairing and segregation are essential events in microsporogenesis in regards to the end product the pollen grain fertility, though most natural and artificial autotetraploids frequently display an expressive decrease in pollen fertility. Even though the giant mutant showed a higher value for the total percentage of abnormalities when compared to the seedless mutant as well as to the parental 'Niagara Rosada' (11.99\%, Pierozzi and Moura, 2014), this did not hinder pollen viability considered as high value. Although a high percentage of pollen viability is not a rule in autotetraploid grapevines, and very significant decreases in the percentage of pollen fertility have been reported in at least 48 spontaneous autotetraploid bud sports from 11 different grape cultivars (Wagner, 1958) and from 31 varieties of $V$. vinifera (Staudt and Kassrawi, 1972b).

According to La Combe et al. (2010), the reduction in chiasma frequency per bivalent in natural autotetraploids is a strategy to avoid quadrivalent formation leading to a stable meiosis, which might favor the evolution of disomic inheritance. Nevertheless, neither the spontaneous chromosome duplication of 'Niagara Rosada Gigante' nor the seedless nature of 'Seedless Niagara' mutants was strong enough to affect the average of the chiasma number per chromosome. The higher mean values for chiasma per chromosome in both somatic mutants point to a good affinity between the $V$. vinifera and $V$. labrusca genomes involved in the diploid 'Niagaras' origin, strengthened by the high percentage of pollen fertility observed. Chromosome irregularities however, have been reported in microsporogenesis of different hybrid varieties of $V$. vinifera (Raj and Seethaiah, 1969, 1973; Staudt, 1995), seeing these abnormalities mostly related to the presence of monovalent and multivalent chromosomes, which ultimately reflected in the degree of chiasma mean values, nearly one chiasma perbivalent.

The way spontaneous chromosome doubling occurred in a shoot of the parental 'Niagara Rosada' giving rise to the giant mutant ('Niagara Rosada Gigante') is an intriguing subject. It is likely that it arose because of: (a) a spontaneous failure in the mitotic division of the initial cell of upcoming shoot meristem; or (b) mechanical injuries caused by the seasonal pruning alone or combined to the use of hydrogen Cyanamid, a chemical for dormancy breaking used in the grapevine growing in tropical countries. This treatment could have interfered in the somatic cell division (disturbance in the phragmoplast alignment or in the spindle fibers, for instance) originating a pool of tetraploid meristematic cells. However, the tetraploid condition had already been established at the uncommitted phase ('anlagen') of the latent bud primordia. As expected for a tetraploid, 'Niagara Rosada Gigante' showed a larger pollen and stomata sizes and a lower frequency of stomata per leaf area, and according to Joshi and Verma (2004) these parameters are very often used as initial steps before chromosome analyses to ascertain the polyploidy occurrence.

Seedlessness is a desirable character for flesh fruits and its occurrence in grapevines had already been observed thousands years ago (Varoquaux et al., 2000). Seedless berries have been observed mainly in old cultivars (Stout, 1936; Ray, 2002). The environmental conditions such as low temperatures, changing of light period can induce the arising of seedless fruits (Sato et al., 2001). The seedlessness condition may also be due to pollen abortion giving rise to male sterility (Hu et al., 2007). Nevertheless, it was not the case of the seedless mutant 'Seedless Niagara' that showed a high percentage of pollen fertility, recorded through pollen stainability. The action of the phytohormone gibberellic acid (GA3), widely used in the table grape industry to induce seedlessness in seeded varieties, was cast aside since it was not applied on the parental 'Niagara Rosada' grapevine. It is likely that the stenospermocarpy in the seedless 'Niagara Rosinha' was due to the expression of the presence of the $V v A G L 11$ gene, as proposed by Bergamini et al. (2013) following studies in some seedless grapevines.

Adverse climatic and environmental conditions as well as abiotic stresses can lead to a disturbance in the microsporogenesis, in chiasma formation or in tapetal cell development (De Storme and Geelen, 2014). Although the wrinkling process observed in several tetrads of seedless mutant seems not being related to local climate variations or other edaphic factors and was observed during the three years in the inflorescences collected. Due to the large amount of pollen yield by flowers this tetrad abnormality scored for seedless and the others scored for the giant mutant, did not affect the pollen viability as a whole. 
The great difference between stained cytoplasm (pollen viability) and pollen germination (pollen fertility), may be attributed to the solid agar medium used, which may have not favored a good pollen germination. However, Narasimham and Mukherjee (1970) had already reported a much lower percentage of pollen germination than pollen stainability for four tetraploid varieties of $V$. vinifera.

The higher percentage of flower buds with six stamens in both mutants studied may be due to a disturbance in stamen gene expression, either related to the nature of seedless mutants and autotetraploids or caused, for instance, by external factors such as temperature fluctuation during sprouting. The development and arrangement of grape flowers is a complex process governed by synchronized functioning genes, where a failure in one or more steps during the male whorl differentiation or an epigenetic modification, could disrupt the coordination of this process and give rise to flowers with different anther numbers. Moreover, the intensive viticulture practices can also affect the flower development, as observed by Vasconcelos et al. (2009).

\section{Conclusions}

The abnormalities observed in both 'Niagara' mutants were not strong enough to disturb the microsporogenesis and pollen viability. Therefore, the seedless mutant 'Seedless Niagara ' can be used as pollen donor in selected crossings regarding the desirable seedlessness character, while the giant mutant 'Niagara Rosada Gigante' may be employed as female parent for the obtainment of seedless triploid plants.

\section{Acknowledgements}

The authors wish to thank Mr. Diego Xavier and Mr. Donizete Crispim for fieldwork in the grapevine collection and to Ms Joanne Roberts Serra for reviewing English text.

\section{Conflicts of interest}

The authors declare that there are no conflicts of interest related to this article.

\section{References}

Alexander MP (1980). A versatile stain for pollen, fungi, yeast and bacteria. Stain Technology 55(1):13-18.

Benavente E, Orellana J (1991). Chromosome differentiation and pairing behavior of polyploids: an assessment on preferential metaphase I associations in colchicine-induced autotetraploid hybrids within the genus Secale. Genetics 128(2):433-442.

Bergamini C, Cardone MF, Anaclerio A, Perniola R, Pichierri R, Genghi R, ... Antoniacci D (2013). Validation assay of p3_VvAGL11 marker in a wide range of genetic background for early selection of stenospermocarpy in Vitis vinifera L. Molecular Biotechnology 54(3):1021-1030.

Boss PK, Thomas MR (2002). Association of dwarfism and floral induction with agrape 'green revolution' mutation. Nature 416(6883):847-850.
Collet SAO, Collet MA, Machado MFPS (2005). Differential gene expression for isozymes in somatic mutants of Vitis vinifera $\mathrm{L}$. (Vitaceae). Biochemical Systematics andEcology 33(7):691-703.

De Storme N, Geelen D (2014). The impact of environmental stress on male reproductive development in plants: biological processes and molecular mechanisms. Plant Cell Environment 37(1):1-18.

Gupta RC, Bala S, Shama S, Kapoor M (2013). Cytomorphological Studies in some species of Chrysanthemum L. (Asteraceae). Chromosome Botany 8(3):69-74.

Howell WM, Black DA (1980). Controlled silver-staining of nucleolus organized regions with a protective colloidal developer: a 1-step method. Experientia 36(8):10141015.

Hu Z, Zhang M, Wen Q, Wei J, Yi H, Deng X (2007). Abnormal microspore development leads to pollen abortion in a seedless mutant of 'Ougan' mandarin (Citrus suavissima Hort. ex Tanaka). Journal of the American Society for Horticultural Science 132(6):777-782.

Joshi P, Verma RC (2004). High frequency production of colchicine induced autotetraploids in faba bean (Vicia faba L.). Cytologia 69(2):141-147.

Kumar A, Singh BK, Meena HS, Ram B, Singh VV, Singh D (2015). Cytogenetical investigations in colchicine-induced tetraploids of Brassica fruticulosa: an important wild relative of cultivated Brassicas. Cytologia 80(2):223-230.

Le Comber SC, Ainouche ML, Kovarik A, Leich AR (2010). Making a functional diploid: from polysomic to disomic inheritance. New Phytologist 186(1):113-122.

Maia JDG (2012). A origem da videira Niagara [The origin of Niagara grapevine]. In: Maia JDG, Camargo HA (Eds). O cultivo da videira Niagara no Brasil [The cultivation of Niagara grapevine in Brazil]. Embrapa, Brasiliapp 15-22.

Me G, Sacerdote S, Vallania R(1984). Osservazioni sulla meiosi in cellule del polline di Vitis vinifera L. (cv. Barbera) diploide e tetraploide. [Meiotic observations in the pollen mother cells of diploid and tetraploid $V$. vinifera L. (cv. Barbera)]. Vitis 23:195-201.

Narasimham B, Mukherjee SK (1970). Seed fertility in tetraploid grapes and their crosses with diploids. Vitis 9:177-183.

Olmo HP (1952). Breeding tetraploid grapes. Proceedings of the American Society for Horticultural Science 59:285-290.

ParkSM, Wakana A, Kim JH, Jeong CS (2002). Male and female fertility in triploid grapes (Vitis complex) with special reference to the production of aneuploidy plants. Vitis 41(1):11-19.

Pierozzi NI, Moura MF (2014). Cytological analyses in 'Niagara Branca' grape and in its somatic mutant 'Niagara Rosada'. Notulae Botanicae Horti Agrobotanici Cluj-Napoca 42(2):460-465.

Pimentel-Gomes F, Garcia CH (2002). Estatística aplicada a experimentos agronômicos e florestais [Applied statistics to agronomic and forest experiments].FEALQ, Piracicaba.

Pires EJP, Pommer CV, Passos IRS, Terra MM (1988). Mutante somático sem sementes em videira 'Niagara Rosada' [Seedless somatic mutant in the grapevine 'Rosy Niagara']. Bragantia 47(2):171-176.

Raj AS, Seethaiah L (1969). Karyotype analysis and meiotic studies in three varieties of grapes (Vitisvinifera L.). Cytologia 34(3):475-483. 
920

Raj AS, Seethaiah L (1973). Cytological studies in grape (Vitis vinifera L.). Cytologia 38(4):549-557.

RammingDW (2008). 'Thomcord' grape. HortScience 43:945-46.

Ray PK (2002). Breeding tropical and subtropical fruits. Narosa Pub. House, NewDelhi.

Reisch BI, Pratt C (1996). Grapes. In: Janick J, Moore JN (Eds). Fruit Breeding, volume II: Vine and Small Fruits Crops. John Wiley \& Sons Inc., New Jerseypp 297-369.

Sato S, Peet MM, Gardner RG (2001). Formation of parthenogenetic fruit, undeveloped flowers and aborted flowers in tomato under moderately elevated temperature. Scientia Horticulturae 90:243-245.

Srivastava HC (1977). Chromosome behavior of a spontaneous autotetraploid guava (Psidium guajava L.). Cytologia 42(3-4):389-394.

Sousa JSI (1959). Mutações somáticas em videiras [Somatic mutations in grapevine]. Bragantia 18(27):387-415.

Staudt G(1995). Some remarks on triploid grapevines. Vitis 34(2):129-130.

Staudt G, Kassrawi M (1972a). Die meiosis von di- und tetraploidem Vitis vinifera 'Riesling' [The meiosis of di and tetraploids Vitis vinifera 'Riesling']. Vitis 11:89-98.
Staudt G, Kassrawi M (1972b). Die Pollenfertilität di-und tetraploider Reben Vitis vinifera 'Riesling' [Pollen fertility of di and tetraploid grapevine Vitis vinifera 'Riesling']. Vitis 11:269-279.

Stout AB (1936). Seedlessness in grapes. New York State Agricultural Experimental Station, Geneva.

This P, Lacombe T, Thomas MR (2006). Historical origins and genetic diversity of wine grapes. Trends in Genetics 22(9):511-519.

Varoquaux F, Blanvillain R, Delseny M, Gallois P (2000). Less is better: new approaches for seedless fruit production. Trends in Biotechnology 18(6):233-242.

Vasconcelos MC, Greven M, Winefield CS, Trought MCT, Raw V (2009). The flowering process of Vitis vinifera: a review. American Journal of Enology and Viticulture 60(4):411-434.

Vezzulli S, Leonardelli L, Malossini U, Stefanini M, Velasco R, Moser C (2012). Pinot Blanc and Pinot Gris arose as independent somatic mutations of 'Pinot Noir'. Journal of Experimental Botany 63(18):6359-6369.

Wagner $\mathrm{E}$ (1958). Über spontane tetraploide mutanten von Vitis vinifera $\mathrm{L}$. [About a spontaneous tetraploid mutant in Vitis vinifera L.]. Vitis 1:197217. 